\title{
ESTUDO DE CASOS DE INOVAÇÕES NAS RECUPERAÇÕES DE CRÉDITO DE PESSOAS JURÍDICAS EMPRESÁRIAS
}

\author{
STUDY OF CASES OF INNOVATIONS IN CREDIT RECOVERIES OF ENTREPRENEUR \\ LEGAL ENTITIES
}

\section{Lilia Maia de Morais Sales}

\begin{abstract}
Doutora em Direito Constitucional pela Universidade Federal de Pernambuco, Recife, PE, Brasil; pós-doutora pela Columbia University, Nova Iorque, Estados Unidos da América; professora do programa de pós-graduação stricto sensu da Universidade de Fortaleza, Fortaleza, CE, Brasil; bolsista de Produtividade em Pesquisa do Conselho Nacional de Desenvolvimento Científico e Tecnológico (CNPq). E-mail: lilia@unifor.br
\end{abstract}

\section{Manuela Brito Camara}

Mestre em Direito Constitucional nas Relações Privadas pela Universidade de Fortaleza-UNIFOR. Advogada. E-mail: manuelacamara@hotmail.com

RESUMO: O crédito é um instituto importante para a economia, pois possibilita o investimento e, com isso, ocasiona o progresso econômico. Em razão disso, é essencial que a recuperação de crédito seja eficiente para que não haja um desequilíbrio econômico da relação creditícia, o qual pode atingir a sociedade como um todo. A presente pesquisa tem como objetivo demonstrar possibilidades de inovação nas recuperações de crédito de empresas para que estas tenham uma maior eficiência. Para tanto, será utilizada metodologia descritiva e exploratória com pesquisa bibliográfica, documental e de campo, com entrevistas realizadas com empresas identificadas como inovadoras nas formas de recuperação de crédito. Na exposição dos resultados encontrados, o presente artigo apresenta a necessidade de inovações nas recuperações de crédito de empresas, analisa experiências reais de recuperação de crédito de sociedades empresárias que apresentam soluções inovadoras e, em seguida, expõe a base que permeia tais inovações, explanando as técnicas que possibilitam aludida eficiência. Por fim, em sede de conclusão, destaca que as soluções inovadoras imprimem um novo olhar ao devedor, priorizando-o, o que possibilita que a sua dignidade humana seja garantida.

Palavras-chave: Recuperação de Crédito. Empresas. Inovação. Eficiência.

\begin{abstract}
The credit is a very important institute for the economy because it enables investments in several economic fields and, thus, it causes economic progress. Because of that, it is important that credit recovery is made efficiently so there is no economic imbalance on the credit relationship, which may impact society as a whole. The present research aims to explain how to innovate in credit recoveries of enterprises for they have an increased efficiency. Therefore, these presents the necessity of innovation in the credit recoveries of the enterprises,
\end{abstract}


analyses real experiences of credit recovery of entrepreneur societies that presents innovative solutions and, then, exposes the basis that permeate those innovations, showing the techniques that enable that efficiency. At last, highlights that the innovative solutions bring a new look for the debtor, protecting him, what possibilities that his human dignity be guaranteed. As for the methodology is going to be used descriptive and exploratore, with bibliographic, document and field research.

Keywords: Credit Recovery. Enterprises. Innovation. Efficiency.

SUMÁRIO: Introdução; 1 Inovações nas recuperações de créditos de pessoas jurídicas empresárias para uma maior eficiência; 2 Casos de soluções inovadoras de recuperação de créditos de sociedades empresárias; 3 base estrutural das técnicas inovadoras de recuperação de crédito de sociedades empresárias; Conclusão; Referências.

\section{INTRODUÇÃO}

Sabe-se que as sociedades empresárias são campo fértil para uma intensa perpetração de negócios jurídicos, visto que, para a circulação de bens e serviços no mercado de determinada empresa, é necessário o entabulamento de transações, as quais são empreendidas entre a firma e o cliente, que pode ser pessoa física ou jurídica. Assim, estes negócios jurídicos entabulados na seara empresarial, usualmente, resultam em operações de crédito, de tal forma que a empresa prestadora do serviço ou fornecedora da mercadoria exercerá a prestação contratada, mas receberá a respectiva contraprestação somente em momento futuro, nos moldes do que fora estipulado pelas partes daquele negócio.

Pode-se asseverar que o sentido jurídico de crédito diz respeito a toda prestação efetivada através de uma operação monetária mediante uma contraprestação correspondente futura. Tal transação é caracterizada pela existência de um transcurso de um intervalo de tempo entre a entrega da prestação e o recebimento da contraprestação. Em razão disso, é fundamental que o credor confie na solvência do devedor, já que este saldará o débito somente em momento posterior (RIZZARDO, 2003, p. 16).

Há, então, um risco nas operações de crédito, motivo pelo qual o credor atua no sentido de obter todas informações acerca daquele contratante da operação creditícia com o escopo de averiguar a sua capacidade de pagamento e, dessa forma, diminuir os riscos (THOMAZI; PAULA, 2020, p. 104).

Por conseguinte, como o crédito concede uma prestação atual para que a contraprestação seja cumprida em momento futuro, constata-se que ele confere poder de compra aos seus beneficiários e, portanto, possibilita a satisfação das necessidades dos seres humanos e, consequentemente, ocasiona desenvolvimento da economia de determinado país (SADDI, 2007, p. 282).

Tal fato decorre de que os créditos viabilizam o investimento, de maneira que, por meio do dinheiro, obtém-se insumos, além de que se incrementa e desenvolve os meios de produção de determinada sociedade, em que os investidores captam o crédito para obter cada vez mais lucro e reinserir tais lucros na economia, havendo um círculo vicioso, que compõe a base do progresso econômico (MALHEIROS, 2019, p. 138).

Dada a relevância do crédito, é imprescindível que, quando haja o inadimplemento, a recuperação desses valores seja eficaz, pois um desequilíbrio da relação creditícia pode ocasionar retração da oferta de crédito e, por conseguinte, reprimir o progresso da economia.

Nesse contexto, faz-se o seguinte questionamento, o qual deverá ser respondido no decorrer desta pesquisa: Como inovar nos procedimentos de recuperações de crédito das pessoas jurídicas empresariais para se ter uma maior eficiência? 
Nesse viés, a presente pesquisa tem como objetivo analisar como as inovações nas recuperações de crédito das sociedades empresárias podem trazer uma maior eficiência para tal procedimento, com a apresentação de casos que demonstram experiências exitosas de retomada de valor creditícios a partir da utilização de técnicas inovadoras para, por fim, demonstrar a base estrutural dos métodos aplicados nessas inovações, os quais podem e devem ser replicados por outras empresas.

Apresenta-se, desta feita, uma pesquisa de conteúdo doutrinário, ou seja, bibliográfica, por meio de obras que tratam direta e indiretamente do assunto ora abordado; documental, com base na legislação brasileira atinente ao assunto, em dados oficiais e em experiências de recuperação de crédito; e de campo, por meio da realização de entrevistas com empresas que desenvolvem sistemas inovadores de recuperação de crédito.

A pesquisa será pura quanto à obtenção de resultados, qualitativa quando à abordagem e descritiva e exploratória quanto aos objetivos, uma vez que buscará descrever, explicar, classificar, esclarecer e interpretar o fenômeno observado, bem como objetivará aprimorar as ideias com informações relativas aos meios extrajudiciais de recuperação de crédito de pessoas jurídicas empresariais.

O presente estudo mostra-se relevante para evidenciar as inovações que podem ser aplicadas nas recuperações de crédito de sociedades empresárias, bem como a consequência jurídica que essas inovações podem ocasionar.

No desenvolvimento, realiza-se uma abordagem acerca da imprescindibilidade de inovações nas recuperações de crédito de empresas para que haja uma maior eficiência, explanando a razão da necessidade do implemento de tais inovações.

Sucede-se com a análise de experiências inovadoras de recuperação de crédito de empresas, na qual se esquadrinha os métodos eficazes utilizados por cada pessoa jurídica empresarial observada.

Em desfecho, examina-se a base estrutural das técnicas inovadoras e eficientes identificadas na análise dos casos mencionados e explana-se os métodos que apresentam correspondência entre si para, então, mencionar a consequência jurídica das inovações nas recuperações de crédito de pessoas jurídicas empresárias

Constata-se, assim, que os métodos examinados possibilitam uma garantia de efetivação da dignidade humana dos devedores, uma vez que as técnicas ali utilizadas provocam emoções positivas nestes, além de que evitam a prática de condutas excessivas que possam macular a integridade psíquica e física do inadimplente, de forma a valorizá-lo.

\section{INOVAÇÕES NAS RECUPERAÇÕES DE CRÉDITOS DE PESSOAS JURÍDICAS EMPRESÁRIAS PARA UMA MAIOR EFICIÊNCIA}

O responsável por recuperar o crédito de sociedades empresárias, na tentativa de reaver os valores, trata com seres humanos, os quais são clientes e tomadores do crédito da empresa credora. Esses indivíduos são dotados de sentimentos e, por isso, necessitam de uma atenção personalizada com uma compreensão por parte do credor. Ressalta-se que uma abordagem inadequada pode prejudicar o alcance do objetivo de retomar eficazmente a quantia creditícia.

Então, primordial haver inovações nos procedimentos de recuperação de crédito de sociedades empresariais para que se tenha um atendimento aos anseios do devedor e cliente e, consequentemente, seja possível que o credor retome de modo satisfatório e eficaz os valores que lhe cabem, mas, concomitantemente, preserve a relação com o freguês da empresa credora.

Uma pesquisa realizada pelo Fórum Econômico Mundial (World Economic Forum), no ano de 2016, indicava que, em 2020, o mercado de trabalho necessitaria, de seus profissionais, habilidades diversas das que se mostravam como importantes no ano de realização da pesquisa. 
Essa alteração decorre das transformações sociais provocadas pela Quarta Revolução Industrial, que se encontra em andamento.

Os resultados da pesquisa destacam a importância das seguintes habilidades: resolução de problemas complexos, pensamento crítico, criatividade, gestão de pessoas, interação com os outros, inteligência emocional, tomada de decisões, orientação do serviço, negociação, flexibilidade cognitiva. Logo, imprescindível que o gestor do conflito do século XXI esteja dotado de tais competências para melhor resolver o problema objeto da lide.

Ainda nesta perspectiva, uma pesquisa realizada pela empresa multinacional de consultoria Accenture questionou mais de 400 executivos estadunidenses quais as habilidades mais procuradas ao contratar. Dentre as primeiras listadas estão a capacidade de resolver problemas, liderança, comunicação, tecnologia e a gestão de pessoas. Os conhecimentos técnicos da indústria figuram somente na sexta posição (ACCENTURE, 2013, online). Verifica-se que as habilidades de resolução de problemas, comunicação e gestão de pessoas estão intrinsecamente relacionadas à gestão de conflitos.

No que se refere ao Brasil, a revista Exame (2016, online) publicou pesquisa elaborada pela empresa de consultoria em educação corporativa AfferoLab, que aferiu e listou as competências mais escassas no mercado de trabalho brasileiro. As competências encontradas, da mais escassa para a menos escassa, foram: resolução de problemas complexos, pensamento crítico, atitude empreendedora, criatividade, habilidade para trabalhar com diferentes culturas, habilidade para comunicação oral e escrita, raciocínio lógico, facilidade para se relacionar, facilidade de aprender e habilidades matemáticas e numéricas.

Percebe-se, assim, que a realidade nacional está alinhada com o contexto global, de maneira que a gestão de conflitos e, notadamente, as ações de recuperação de crédito carecem de atualização. Pode-se afirmar, então, que as inovações nas gestões de conflito de recuperação de crédito, sejam tecnológicas ou estruturais, devem ser capazes de possibilitar que o gestor da controvérsia aperfeiçoe as habilidades perquiridas pela Quarta Revolução Industrial a atenda aos anseios das partes envolvidas na contenda. Isso decorre do fato de que mencionadas inovações deverão permitir o estímulo à resolução de problemas complexos, à melhor coordenação de pessoas com inteligência emocional, à criatividade, ao pensamento crítico, à tomada de decisões, à flexibilidade cognitiva e à negociação.

As técnicas que envolvem comunicação direta, oitiva aberta, gerenciamento de emoções, valorização das outras pessoas por intermédio da empatia, formulação de soluções novas para o problema, dentre outras, têm o condão de provocar inovações nas recuperações de créditos de sociedades empresárias. Estas representam métodos de negociação em sentido amplo, aplicáveis aos mais diversos tipos de resolução alternativa de conflito, seja a conciliação, a mediação ou a negociação em sentido estrito. Por conseguinte, afirma-se que esses métodos visam alcançar as soluções da demanda e, se possível, a preservação da relação das partes envolvidas na contenda, qual seja cliente e fornecedor.

Observa-se que até o ano de 2018, três práticas são comuns na cobrança extrajudicial de dívidas. São elas: ligações telefônicas em horários inadequados, concessão de prazos unilateralmente pré-estabelecidos e uso de constrangimento para pagamento do débito.

Quanto à conduta de realizar ligações telefônicas em horários inadequados, destaca-se que é comportamento comum de algumas empresas efetuarem telefonemas impessoais e reiterados aos seus devedores, com o intuito de recuperarem seus créditos, utilizando, no entanto, tom impositivo acerca do pagamento da dívida. Com frequência, os mencionados contatos são estabelecidos em horários inconvenientes, fato que faz gerar insatisfação nos clientes inadimplentes da empresa credora, uma vez que eles, usualmente, entendem como inapropriado o recebimento de muitas ligações ao longo do dia até que a dívida seja paga.

Em relação ao fato de as empresas concederem curtos prazos pré-estabelecidos unilateralmente para adimplemento da dívida, afirma-se que tal prática também pode não gerar 
resultados positivos nas retomadas dos créditos empresariais em comento. As firmas, muitas vezes, pelo volume das demandas, ao efetuarem as cobranças, concedem unilateralmente curtos prazos pré-estabelecidos para que haja o adimplemento do débito em tempo hábil. Ao estabelecer unilateralmente o prazo, a empresa não promove, junto ao devedor, consenso sobre o lapso temporal para o pagamento e nem mesmo a situação real e específica do inadimplente é levada em consideração para a fixação de prazos mais adequados e eficazes para a quitação. Muitos devedores podem ter interesse de pagar a dívida, mas, sem haver uma negociação dos prazos, pode-se tornar inviável o adimplemento.

No tocante à utilização de mecanismos de constrangimento ou ameaças, pontua-se que, geralmente, as empresas credoras utilizam-se, já em um primeiro momento, de argumentos que constrangem o cliente como inserção do nome do devedor em órgãos de restrição de crédito e/ou o ajuizamento de demanda judicial para o crédito ser reavido por meio do Poder Judiciário. A aludida prática estimula uma maior indisposição no devedor e faz que este repudie o contato, dificultando, assim, a resolução do conflito.

As medidas apontadas têm o viés de causar intranquilidade e insatisfação nas pessoas, além de estimular reações negativas, dificultando a comunicação e a solução para o problema e, consequentemente, a recuperação do crédito. Por essa razão, tem-se verificado que certas empresas têm se destacado com soluções inovadoras na recuperação de seus créditos, de modo que utilizam técnicas que diferem das supramencionadas, as quais são capazes de trazer resultados eficientes.

Desse modo, repisa-se que a necessidade das inovações no campo da recuperação de crédito das empresas decorre da importância de observar os anseios das partes do conflito, bem como da relevância de aperfeiçoar as habilidades perquiridas pela $4^{\mathrm{a}}$ Revolução Industrial, para que se tenha uma maior eficiência da recuperação de crédito e, então, haja um equilíbrio da relação creditícia com o progresso da economia do país, visto que o crédito possibilita o desenvolvimento econômico da sociedade (SCHUMPETER, 1978, p. 102).

\section{CASOS DE SOLUÇÕES INOVADORAS DE RECUPERAÇÃO DE CRÉDITOS DE SOCIEDADES EMPRESÁRIAS}

Tendo em vista a importância de soluções inovadoras nas recuperações de crédito de empresas, necessário se faz analisar casos que apresentaram maior eficiência em razão de terem implementados inovações nos métodos de retomadas de valores creditícios empresariais. Assim, examina-se recuperações de crédito de empresas realizadas por meio de portal online de negociação, de aplicativos de celulares e tablets e de feirões de negociação.

Primeiramente, cita-se o caso do Banco do Brasil, que, utilizando o método da negociação - no qual as próprias partes em conflito atuam por conta própria para resolver a contenda - criou um portal para possibilitar negociações via Internet a partir da ideia de um funcionário seu. Nesse portal, o devedor espontaneamente consulta o valor do seu débito e propõe uma negociação para saldar a dívida. Trata-se de uma forma inovadora de resolução de conflito, já que utiliza a tecnologia para solucionar problemas de recuperação de crédito.

O cliente tem a autonomia de selecionar a opção de pagamento após a consulta do saldo devedor. Ele escolhe ainda pela possibilidade de obtenção de desconto ou não, todavia, para os devedores que optam pela redução dos valores, há o impedimento de contratação de novos serviços de crédito daquele estabelecimento enquanto não houver o pagamento integral do valor creditício. As negociações solicitadas pelos clientes inadimplentes são avaliadas por um algoritmo que pontua a probabilidade de recuperação do crédito negociado (BRASIL, 2015, online).

No período de um ano, entre 2014 e 2015, por meio do referido portal, o banco efetuou negociações com 146 (cento e quarenta e seis) mil clientes, as quais totalizaram cerca de um bilhão e meio reais de recuperação de valores inadimplidos. As negociações feitas pela instituição financeira com pessoas físicas ultrapassaram, o montante de 1 (um) bilhão de reais, em contratos 
com mais de 138 (cento e trinta oito) mil clientes. Já as negociações realizadas com mais de 7 (sete) mil pessoas jurídicas, totalizaram a renegociação de 440 (quatrocentos e quarenta) milhões de reais. Nas mencionadas negociações, a maioria dos clientes optou por fazer acordo sem desconto para ficaram possibilitados de contrair novos serviços de captação de crédito bancário (ÉPOCA NEGÓCIOS, 2015, online).

Atesta-se, portanto, a eficiência da recuperação de crédito de empresas por meio da negociação e, mais especificamente, por intermédio da negociação online. Verifica-se que, em um interregno de um ano, foram realizadas 146 (cento e quarenta e seis) mil negociações de dívidas.

A empresa credora investiu na criação do sistema, produzido uma única vez para ser replicado em diversas outras operações, de modo que há a dispensa da contratação de advogados ou de outros profissionais que poderiam realizar a negociação e ainda não se tem o pagamento de despesas financeiras para impulsionar a negociação. Ademais, o sistema criado possibilita uma rápida resolução de conflito, tendo em vista que, em um curto espaço de tempo, foram entabuladas milhares de negociações e recuperados bilhões de reais de créditos.

Percebe-se que estas inovações inseridas no bojo deste tipo de resolução de conflito ocasionam recuperação de crédito com custo baixo, retomada do valor devido ao credor em menor espaço de tempo e em quantidades satisfatórias, além da possibilidade de continuidade da relação da empresa com o cliente, já que são proporcionados ao consumidor benefícios, como concessão de descontos e possibilidade de escolha na forma de pagamento da dívida diante das opções apresentadas pela credora, os quais o fazem ter o intento de voltar a entabular negócios jurídicos com aquele estabelecimento.

Menciona-se também o caso do aplicativo Debt, o qual fora desenvolvido para negociações de dívidas por meio de smartphones ou tablets. Para o funcionamento do programa, necessita-se de conexão com a rede mundial de computadores para haver a ligação entre credor e devedor. É indispensável, para a conexão, que tanto a empresa credora quanto o devedor estejam cadastrados no aplicativo.

Tal aplicativo se trata de um canal direto, por meio do qual o devedor pode negociar imediatamente com a empresa credora ou com seu representante. A empresa criadora do aplicativo destaca que é concedida ao devedor certa autonomia, pois a firma credora oferece as opções e o inadimplente escolhe como prefere pagar, contando com a alternativa de obter descontos, de modo que a composição é coordenada pelo devedor (TASKEN, 2018, online).

A referida sociedade empresária aponta algumas vantagens do sistema de recuperação de crédito em comento. Há o fim do constrangimento de ligações telefônicas de cobrança em horários inconvenientes, já que são dadas ao devedor as opções de formular conversa no aplicativo com a empresa credora e de solicitar ligação no horário desejado em que julgar adequado. Acontece também a negociação da dívida de forma ágil e segura, pois os acordos são privativos e disponíveis somente para o usuário do aplicativo, que, no caso, é o devedor. Tem-se maior organização das dívidas do inadimplente, pois é possível que ele acompanhe seus débitos pelo aplicativo com o controle dos acordos e dos seus respectivos prazos de vencimentos e boletos.

Em pesquisa de campo realizada com a empresa Tasken, criadora do aplicativo, esta informou, por meio de Luana Mesquita, responsável pelo setor de Recursos Humanos da firma, conforme anexo deste artigo científico, que a sociedade empresária em comento foi criada "para oferecer as melhores ferramentas e soluções para otimizar as operações de cobrança". Foi explicitado ainda, por intermédio da aludida pesquisa, que a plataforma de inovação por eles criada, a qual inclui o aplicativo em comento, um sistema operacional de recuperação de crédito com funções automáticas e um módulo de atualização instantânea de dados do credor, gera mais de 750 (setecentos e cinquenta) mil operações por dia, as quais totalizam mais de 6 (seis) bilhões de reais em transações.

Não obstante a empresa entrevistada não ter individualizado os valores percebidos por cada sistema da sua plataforma, a qual engloba o três aludidos programas, no sítio eletrônico do 
aplicativo Debt, é possível ver que este programa específico, desde o início de sua operação, em março de 2016, até 2018, perfectibilizou o cadastramento de mais de 3 bilhões de reais em dívidas e a recuperação de mais de 5 milhões de reais.

Quando do questionamento acerca do impacto que a empresa tem causado no mercado, o qual poderia ter sido exteriorizado por meio de valores ou percentuais médios que as credoras recuperavam antes e depois da contratação deste sistema, a empresa informou que os seus clientes não revelam valores ou percentuais sobre as recuperações de crédito empreendidas por eles, no entanto, informaram que o sucesso da empresa criadora do aplicativo tem sido reconhecido com a conquista de alguns prêmios representativos, como o "Best Performance de inovação no mercado de cobrança", no ano de 2016.

Apesar dos valores recuperados pelas credoras não terem sido demonstrados antes e depois da contratação do serviço da empresa entrevistada - o que poderia ilustrar melhor o caso estudado com um comparativo - o número expressivo de transações já realizadas com o respectivo montante monetário recuperado pelas firmas credoras utilizadoras de tal sistema externam a eficiência das inovações inseridas na recuperação de crédito de empresas.

A sociedade empresária entrevistada desenvolveu o aplicativo e cobra um valor desconhecido para que empresas que almejem recuperar créditos o utilizem. Ela garante que os valores cobrados são menores até mesmo do que os gastos oriundos das formas tradicionais de cobranças de dívidas extrajudiciais, apontando que o custo do aplicativo corresponde apenas a $4 \%$ (quatro por cento) da despesa gerada pelo uso da carta de cobrança, que é prática comum em negociações extrajudiciais de recuperação de crédito.

Não obstante os valores recuperados no primeiro caso analisado terem sido mais significantes, é possível verificar também a eficiência da recuperação de crédito de sociedades empresárias quando da resolução do conflito por meio da negociação com o mencionado tipo de ferramenta, visto que, em um lapso temporal de 2 (dois) anos, quantidades consideráveis foram retomadas dos inadimplentes com a geração de um custo mínimo para a empresa credora.

Em seguida, aponta-se o caso de feirões de negociação empreendidos pela empresa concessionária de energia elétrica no Ceará, a Enel, anteriormente denominada Coelce. Tal companhia, em alguns meses do ano, realiza "feirões" de negociação, nos quais ela oferece ao inadimplente política diferenciada de pagamento e propõe a quitação da dívida sem juros e de maneira parcelada, mediante o pagamento de uma entrada reduzida. A forma do parcelamento, geralmente, depende das condições específicas de cada cliente.

A mencionada empresa costuma anunciar a realização desses feirões, os quais geralmente duram em média 15 (quinze) dias, para todo o público, de maneira que o devedor que desejar findar sua situação de inadimplência pode dirigir-se ao estabelecimento da Enel para firmar negociações da dívida com os benefícios propostos e, assim, resolver o conflito.

Destaca-se que o cliente devedor pode negociar o débito a qualquer tempo com a referida empresa credora, no entanto, as condições especialíssimas de pagamento, com os referidos benefícios, só são processadas nos feirões realizados. Isso não quer dizer que o devedor não terá vantagem alguma em negociar o débito fora desse evento, mas implica que os benefícios serão diferentes.

No ano de 2015, nos meses de julho a novembro, a Enel efetuou "feirões" com as tais condições e registrou a consecução de 12.258 (doze mil, duzentos e cinquenta e oito) negociações com parcelamentos das dívidas (O POVO, 2016, online). Já no transcorrer de 2016, a referida empresa efetivou outros "feirões" e realizou 38.274 (trinta e oito mil e duzentos e setenta e quatro) negociações com parcelamentos dos débitos de seus devedores (G1, 2017, online). 
Apesar de a empresa ora analisada não divulgar os valores transacionados nestas negociações ${ }^{1}$, os números representativos da quantidade de acordos transacionados demonstram a eficiência que este método pode trazer às recuperações de crédito de pessoas jurídicas empresariais.

Em um interregno de um ano e meio, a empresa ora estudada teve o aumento consecutivo da quantidade de acordos oriundos das negociações empreendidas com o objetivo de recuperar seus créditos, totalizando, neste lapso temporal, o número de 50.532 (cinquenta mil, quinhentos e trinta e dois) transações. Desse modo, diante da quantidade numérica das negociações entabuladas, constata-se que patente a maior eficiência deste método inovador de resolução do conflito ora analisado.

Por fim, apresenta-se a negociação empreendida pelo escritório de advocacia denominado Rufino Pontes Advocacia para recuperar créditos de uma sociedade empresária do segmento de turismo. Os fundadores do escritório afirmam que o criaram com intuito de oferecer uma advocacia inovadora, com foco na prevenção de litígios, acreditando que seus serviços poderiam fazer a diferença.

Então, os serviços do escritório foram contratados pela referida empresa, a qual possui 30 (trinta) anos de atuação no mercado, com matriz em Fortaleza, no Ceará, e filiais nos estados de Pernambuco e São Paulo. A mencionada pessoa jurídica empresarial, até o ano 2016, cobrava informalmente seus devedores, sem técnicas apropriadas para tanto, o que fez com que acumulasse créditos de 85 devedores, cuja soma ultrapassava o montante de 1 (um) milhão de reais. Com tantos valores creditícios a recuperar, o sócio da empresa expôs ao escritório que precisa reaver tais quantias com agilidade e eficiência.

Por conseguinte, o escritório em comento disse que foi necessário vislumbrar o que seria importante para o devedor, exercitar a habilidade de se colocar no lugar do outro e projetar a posição das pessoas que procuravam os serviços da empresa de turismo, momento em que foi identificado que imprescindível tratar tais clientes com criatividade e empatia. Nesse viés, em resposta ao oficio enviado para a pesquisa de campo, foi ressaltado que, desde o início das comunicações estabelecidas com os devedores, os advogados procuravam reformular o discurso ao informar que a empresa tinha o interesse de restabelecer a relação comercial, além de recuperar o crédito devido a ela.

O escritório menciona que enviou 16 (dezesseis) notificações extrajudiciais com o fito de cientificar os devedores da dívida para que eles procurassem a empresa credora para firmar um acordo e pagar o débito consensualmente. Das 16 (dezesseis) notificações extrajudiciais enviadas, 14 (quatorze) obtiveram êxito com o firmamento de negociações em relação ao conflito de recuperação de crédito anteriormente instalado.

Antes do envio da notificação pelo escritório, a empresa, por intermédio do seu setor de contas a receber, entrava em contato com os devedores e formalizava a cobrança por meio de ligação telefônica como uma primeira tentativa para solucionar a lide. Após o envio das mencionadas notificações, quando havia possibilidade de negociação com algum devedor, esta era passada ao controle do escritório advocatício contratado, o qual se colocava à disposição para sanar dúvidas e esclarecimentos em reuniões presenciais, nas quais se obteve mais sucesso devido à oportunidade de estar frente a frente com o devedor, quando foi possível compreender um pouco mais as razões de seu inadimplemento.

Além dos aludidos casos fora da seara judicial, foram ajuizadas 55 (cinquenta e cinco) ações, em razão de estratégia processual, visto que alguns débitos datavam quase cinco anos e, por isso, estava próximo de ser operada a prescrição ${ }^{2}$. Dessas ações, até a realização da pesquisa de campo efetuada em de março de 2018, foram finalizadas 13 (treze) processos judiciais por meio de

\footnotetext{
${ }^{1}$ Em ofício enviado à empresa analisada, solicitou-se que fosse informado os valores creditícios recuperados antes e depois da adoção dos métodos em comento, contudo, tal pleito não foi atendido por questões de segurança da empresa. ${ }^{2}$ Prescrição é um instituto que regula a perda do direito de acionar judicialmente para pleitear determinado direito, devido ao decurso de certo período de tempo preconizado pela lei, conforme o artigo 189 do Código Civil de 2002.

Revista de Direito Brasileira | Florianópolis, SC | v. 27 | n. 10 | p.315-329 | Set./Dez. 2020
} 
acordos realizados no âmbito extrajudicial. Todos os casos mencionados na resposta ao ofício totalizaram, de meados de 2016 até aludida data, a recuperação de 380 (trezentos e oitenta) mil reais.

Neste caso, percebe-se a eficiência deste método de resolução de conflito dotado de inovações quando se vê que, de 16 (dezesseis) tentativas de negociação por meio do envio de notificação extrajudicial, 14 (quatorze) foram exitosas. Ademais, percebe-se que, mesmo com o ajuizamento da ação, foi possível firmar acordos na seara extrajudicial por meio de negociações, o que possibilitou uma maior recuperação de crédito em um menor espaço de tempo, quando comparado ao lapso temporal médio de duração de um processo, este apresentado em pesquisa realizada pelo Conselho Nacional de Justiça (CNJ).

A pesquisa mencionada, exposta em relatório elaborado em 2017 referente às ações em curso até 2016 na Justiça Brasileira, aponta a média de 12 anos e 3 meses para a tramitação de um processo na Justiça Estadual para os casos em que o Autor da ação não detenha um título executivo judicial ou extrajudicial ${ }^{3}$ em mãos. Explica-se que o tempo de tramitação de um processo na fase de conhecimento, na Justiça Estadual, perfaz a média de 4 ano e 10 meses, já, na fase de execução, o tempo médio de duração dos processos, também na Justiça Estadual, permeia o lapso temporal de 7 anos e 5 meses $^{4}$ (CONSELHO NACIONAL DE JUSTIÇA, 2017, p. 10).

Diante da análise dos casos acima delineados, é possível verificar que tais soluções de recuperação de crédito de sociedades empresárias trazem em seu bojo inovações que possibilitam uma maior eficiência na retomada dos valores inadimplidos às empresas credoras. Além disso, é possível depreender que os casos analisados possuem bases estruturais semelhantes em seus métodos, as quais, quando identificadas e aplicadas, proporcionam a inovação almejada nos profissionais que enfrentam a $4^{\mathrm{a}}$ Revolução Industrial e atendem os anseios de ambas as partes conflitantes, ocasionado, por conseguinte, uma maior eficiência na resolução da controvérsia.

\section{BASE ESTRUTURAL DAS TÉCNICAS INOVADORAS DE RECUPERAÇÃO DE CRÉDITO DE SOCIEDADES EMPRESÁRIAS}

Identifica-se uma base em comum na estrutura dos sistemas de resolução de conflitos de recuperação de créditos de pessoas jurídicas empresariais analisados no tópico anterior. Essa correspondência de técnicas explicita que as inovações das recuperações de créditos percorrem para um novo viés, qual seja o de imprimir um olhar diferenciado ao devedor, concedendo-lhe benefícios, respeitando a sua autonomia, estimulando a empatia, reformulando o conflito e tratando o inadimplente como parceiro.

É possível verificar que os casos analisados valorizam a autonomia da parte devedora em reconhecer o débito e, espontaneamente, dirigir-se ao endereço eletrônico ou físico da credora para propor o pagamento da dívida na forma que lhe condiz.

Roger Fisher e Daniel Shapiro (2009, p. 77), ao preconizarem acerca da força da emoção na gestão de conflitos, consignam que é primordial que haja um respeito à autonomia de cada parte, sem invadir a individualidade do outro da relação e destacam que essa conduta pode causar impactos positivos na resolução da lide: "se a outra parte se sentir invadida em sua autonomia, possivelmente reduzirá sua confiança em nós, rejeitará nossas ideias, sejam boas ou não, e fará pouco esforço para colaborar com nossa demanda".

\footnotetext{
${ }^{3}$ O Código de Processo Civil de 2015 determina, em seu artigo 784, quais são os documentos que representam título executivo extrajudicial. Os títulos executivos judiciais são aqueles que são materializados por uma sentença judicial.

${ }^{4}$ Destaca-se que o parâmetro utilizado foi a Justiça Estadual em razão de que as recuperações de créditos de empresas dão-se, em grande maioria, neste âmbito, de modo que tais ações serão processadas na Justiça Federal quando a União, entidade autárquica ou empresa pública federal figurarem como devedoras, assistentes ou oponentes, nos termos do artigo 109 da Constituição Federal Brasileira de 1988.
} 
Percebe-se também que os referidos casos visam a concessão de vantagens mútuas às partes com a solução da controvérsia, de tal modo que ao devedor é propiciado o pagamento da dívida na forma escolhida por ele e com descontos e ainda é permitido, como no caso do Banco do Brasil, entabular novos contratos a depender da forma de pagamento escolhida, o que, mais uma vez, ressalta a autonomia do inadimplente, já ao credor é proporcionado o recebimento do crédito.

Denota-se, então, que a criatividade das partes se mostrou como elemento importante para constatar o que seria vantajoso e traria benefícios para ambas, o que facilita o encontro do consenso entre elas (GUNTHER; MACHADO; MEDRADO, 2019, p. 181).

William Ury, Roger Fisher e Bruce Patton (2014, p. 82) salientam que "independentemente do interesse conjunto de se evitar uma perda mútua, quase sempre existe a possibilidade de um ganho comum". Então, entende-se que é importante que haja a clara identificação de interesses compartilhados pelas partes para que elas fiquem satisfeitas com as propostas e entabulem o acordo, de modo que se torna essencial que a pessoa se sinta suficientemente satisfeita com o pacto para que este seja cumprido. Isso corrobora com a eficiência da negociação, pois, se o devedor livremente se dirigiu ao credor para pagar a dívida com uma proposta que lhe trouxe satisfação, haverá grandes probabilidades deste acordo ser cumprido.

Verifica-se ainda que os casos analisados são objetivos, atendo-se a resolver o problema e distanciando o foco de fatos passados que provocaram o litígio e o não pagamento da dívida. Eles têm o fito de encontrar soluções para o firmamento do acordo, de modo que recusam a discussão de atos negativos cometidos por uma das partes, pois tal debate não acrescentaria positivamente na resolução da controvérsia em razão destes atos já terem acontecidos. A técnica em comento separa a pessoa da desavença e possibilita uma cooperação na resolução da lide pelas partes, em que trabalham lado a lado, desvencilhando o problema (FISHER; URY; PATTON, 2014).

Ademais, constata-se que, nos casos estudados, evitou-se a utilização de ameaças para compelir o pagamento da dívida, de tal forma que se priorizou trazer soluções para o pagamento do débito. Nesse diapasão, Ury, Fisher e Patton (2014) ressaltam que fazer uma oferta positiva para a resolução do conflito é mais eficaz que uma ameaça, de modo que os casos ora estudados, que propõem o pagamento espontâneo pelo devedor para autonomamente resolver o conflito, externam a eficácia desta técnica.

Observou-se também que, nos casos apresentados, o devedor foi capaz de conduzir a negociação e colaborar para o firmamento do acordo, sem que houvesse imposições pela empresa credora. Mencionada técnica provoca uma comunicação colaborativa, por meio da qual as pessoas são apresentadas como colaboradoras na resolução do problema e não como opositoras, fato que possibilita a união de possíveis interesses em comum (SALES, 2010; FISHER; SHAPIRO, 2009).

Tal técnica empodera as partes em conflito, inclusive o devedor, pois, por meio do diálogo colaborativo, elas próprias conseguem identificar as possíveis soluções para a controvérsia e, assim, resolvê-las (SALES; LIMA, 2019, p. 273).

Além disso, notou-se que os métodos estudados no tópico acima expõem primeiramente o interesse da parte credora de negociar seus créditos para, em seguida, apresentar as propostas específicas de pagamento, o que ocasiona uma melhor compreensão e escuta dos argumentos. Roger Fisher, William Ury e Bruce Patton (2014, p. 66) afirmam que essa técnica é bastante eficaz e dizem que "se você deseja que alguém ouça e entenda seus argumentos, comece pelos seus interesses e ponderações e só depois ofereça suas conclusões e propostas".

Outrossim, verificou-se que, nos casos analisados, priorizou-se tratar o devedor como parceiro, explicitando o intento da empresa em que ele volte a entabular negócios com aquele estabelecimento empresarial. Roger Fisher e Daniel Shapiro (2009, p. 61) entendem que, em uma resolução consensual de conflitos, é necessário que seja promovida a afiliação, por meio da qual se deve tornar o adversário um parceiro, tratando-o como colega e reconhecendo os possíveis vínculos existentes entre as partes. 
A afiliação é eficiente por ser capaz de promover uma conexão emocional entre as pessoas, provocando emoções positivas entre elas e facilitando o encontro do consenso, de tal forma que o estabelecimento dessa conexão instaura uma conjuntura harmônica e equilibrada entre os participantes da lide (BRANDÃO, 2019, p. 35).

Por fim, averiguou-se que as empresas estudadas provocam um estímulo à empatia nas recuperações de seus créditos, de modo que procuraram compreender as razões que levaram o devedor ao inadimplemento ou os sentimentos e interesses destes, condutas que fizeram as empresas credoras colocarem-se no lugar dos devedores e verem o conflito por outro ângulo, facilitando, assim, o entabulamento do acordo.

Em reflexões anteriores acerca da mediação, que utiliza as mesmas técnicas da negociação, todavia, estas são aplicadas por um terceiro imparcial, percebeu-se a eficiência da empatia para solucionar conflitos, em que a utilização desse método reformula situações, bem como propicia um olhar diferente acerca da contenda, de forma a estimular o encontro de convergência das partes e a identificar os conflitos reais que causaram o desconforto, propiciando, então, a solução da lide (SALES; ANDRADE, 2018, online).

Percebe-se que, para o exercício da empatia, primordial a escuta ativa com a oitiva atenta da percepção do conflito pela parte adversa, sem julgamentos em relação a ela, prática que promove a conexão entre os indivíduos e, por conseguinte, facilita a resolução do problema (REIS, 2019, p. $18)$.

Desta feita, depreende-se que as técnicas retromencionadas são eficazes em razão de provocarem emoções positivas nos devedores e, assim, possibilitarem a resolução do conflito com a consequente recuperação de crédito. $\mathrm{O}$ foco no consumidor valoriza-o, de forma que os credores passam a não praticar condutas excessivas que possam macular a integridade psíquica e física daquele.

Nesse diapasão, é possível afirmar que essas técnicas, além de atenderem os anseios de ambas as partes da relação creditícia e trabalharem habilidades exigidas pela $4^{\mathrm{a}}$ Revolução Industrial, ocasionam uma garantia de preservação da dignidade humana dos indivíduos inadimplentes.

Daniel Sarmento (2010, p. 89) aduz que "o principio da dignidade da pessoa humana nutre e perpassa todos os direitos fundamentais que, em maior ou menor medida, podem ser considerados como concretizações ou exteriorizações suas". Por consequência, afere-se que afluem da dignidade da pessoa humana regras e princípios que representam desdobramentos desta com o fito de assegurar a efetividade do corolário máximo de vida digna de todos os cidadãos. Na mesma esteira, Maria Celina Bodin de Moraes (2010, p. 120) apresenta a dignidade da pessoa humana a partir de quatro desdobramentos:

(...) (i) o sujeito moral (ético) reconhece a existência dos outros como sujeitos iguais a ele; (ii) merecedores do mesmo respeito à integridade psicofísica que é titular; (iii) é dotado de vontade livre, de autodeterminação; (iv) é parte do grupo social, em relação ao qual tem a garantia de não vir a ser marginalizado.

Importante destacar também que, apesar de o corolário da dignidade da pessoa humana ter importante relevância para os seres humanos isoladamente, por meio do qual se objetiva a vida digna de cada cidadão em si, este também alcança as relações interpessoais, nas quais os indivíduos estão inseridos, constantemente, na vida em sociedade, de maneira que, quando do alcance da aludida dignidade, necessária a garantia e a proteção de mecanismos que desenvolvam as referidas relações de maneira plena e justa (ALTOÉ; OLIVEIRA, 2020, online).

Logo, a conduta de relacionar-se com o cliente, praticando a empatia e colocando-se no lugar do devedor, o comportamento de evitar contatos em horários constrangedores, a ação de respeitar a autonomia do inadimplente no tocante à resolução do problema, a atitude de reconhecer o devedor como parceiro, o ato de oferecer vantagens a este e a iniciativa de facilitar para o 
inadimplente a solução da lide provoca uma situação de bem-estar nele, diante do intento de estabelecer uma boa relação entre as partes.

Portanto, é afastada uma eventual conduta humilhante em uma possível atuação equivocada nos processos de recuperação de crédito extrajudicial e consensual, a qual poderia abalar integridade psicofísica, a liberdade e a igualdade dos cidadãos, além de afetar as relações interpessoais.

Desse modo, depreende-se que a atitude praticada pela empresa credora no sentido de praticar uma atitude solidária e cooperativa não fere a dignidade do inadimplente, mas ao revés, garante a vida digna dele no aspecto individual e coletivo.

\section{CONCLUSÃO}

Verificou-se que há a necessidade de inovação nas resoluções de conflitos das empresas nos séculos vindouros para que que haja o aperfeiçoamento das habilidades perquiridas pela $4^{\mathrm{a}}$ Revolução Industrial e, desta feita, os anseios dos cidadãos envolvidos no problema sejam atendidos, principalmente dos devedores, por serem clientes da empresa e o vetor da atividade empresarial.

Desse modo, constatou-se que tais inovações são importantes porque são capazes de propiciar uma maior eficiência nas recuperações de crédito de empresas e, então, um equilíbrio da relação creditícia com a retomada do valor inadimplido. Viu-se, assim, que o reestabelecimento do equilíbrio na relação creditícia ocasiona um estímulo ao desenvolvimento econômico, já que o desequilíbrio da relação creditícia pode provocar retração da oferta de crédito e, por conseguinte, reprimir o progresso da economia.

Observou-se que as aptidões necessárias para o enfretamento da sociedade neste período de Revolução Industrial são: resolução de problemas complexos, pensamento crítico, criatividade, gestão de pessoas, interação com os outros, inteligência emocional, tomada de decisões, orientação do serviço, negociação, flexibilidade cognitiva. Ocorre que tais habilidades podem ser trabalhadas por meio de técnicas como comunicação direta, oitiva aberta, gerenciamento de emoções, valorização das outras pessoas por intermédio da empatia, formulação de soluções incomuns para o problema, dentre outras.

As aludidas técnicas dizem respeito aos métodos de negociação em sentido amplo, os quais podem ser aplicados nas mais diversas formas de resolução extrajudicial de conflito, seja por meio da mediação, da negociação em sentido estrito ou conciliação.

Por conseguinte, analisou-se casos de resolução extrajudicial de conflito de recuperações de crédito de empresas que utilizam métodos inovadores, que não correspondem às técnicas empreendidas por grande parte das pessoas jurídicas empresariais até o ano de 2018. Percebeu-se, em seguida, que as inovações verificadas apresentam a mesma base estrutural, com métodos que correspondem entre si, quais sejam: respeito à autonomia das partes, concessão de vantagens mútuas, reconhecimento do status do devedor como parceiro da empresa, objetividade na resolução do problema, prática da empatia, repulsa de ameaças e comunicação colaborativa, por meio do qual ambas as partes auxiliam na solução da lide.

Notou-se que as referidas técnicas são eficazes em razão de provocarem emoções positivas nos devedores e, assim, possibilitarem a resolução do conflito com a consequente recuperação de crédito. Essas emoções positivas decorrem do foco dado ao inadimplente, em que este é valorizado, sem que os credores pratiquem condutas excessivas que possam macular a integridade psíquica e física do inadimplente.

Por fim, foi possível perceber que esse olhar diferenciado aos devedores preconizado pelas inovações identificadas nesta pesquisa respeita seus desejos e interesses e valoriza-os, de modo a proteger a integridade psíquica, a liberdade e a igualdade dos cidadãos inadimplentes, além de desenvolver suas relações interpessoais. Averiguou-se, assim, que as técnicas em comento 
ocasionam uma maior eficiência na recuperação de crédito das empresas, mas também garantem a efetividade da dignidade da pessoa humana do devedor.

\section{REFERÊNCIAS}

ACCENTURE. 2013 Skills and Employment Trends Survey: Perspectives on Training. United States of America: Accenture, 2013.

ALTOÉ, Bruna Agostinho Barbosa; OLIVEIRA, José Sebastião de. Abertura relacional e dignidade da pessoa humana: breves considerações sobre tutela das relações interpessoais como meio de proteção da personalidade. Revista Eletrônica Direito e Sociedade, Canoas, v. 8, n. 1, 2020. Disponível em: https://revistas.unilasalle.edu.br/index.php/redes/article/view/5364/pdf. Acesso em: 04 ago. 2020.

BRANDÃO, Clésia Domingos. Mediação empresarial: uma análise da aplicabilidade e efetividade do instituto nos conflitos entre empresas. 2019. 130 f. Dissertação (Mestrado em Direito). Programa de Pós-Graduação Stricto Sensu. Universidade Nove de Julho, São Paulo, 2019. Disponível em:

https://docs.google.com/viewerng/viewer?url=http://bibliotecatede.uninove.br/bitstream/tede/211 7/2/Clésia+Domingos+Brandão.pdf. Acesso em: 06 ago. 2020.

BRASIL. Constituição (1988). Constituição da República Federativa do Brasil. Brasília: Senado Federal, 1988.

BRASIL. Lei n. 7.357, 10 de janeiro de 2002. Institui o Código Civil. Diário Oficial da União, Brasília, DF, 11 jan. 2002. Disponível em: http://www.planalto.gov.br/ccivil_03/Leis/2002/L10406compilada.htm. Acesso em: 07 nov. 2017.

BRASIL. Lei n. 13.105, de 16 de março de 2015. Código de Processo Civil. Diário Oficial da União, Brasília, DF, 2015. Disponível em: http://www.planalto.gov.br/ccivil_03/_ato20152018/2015/lei/113105.htm. Acesso em: 17 nov. 2017.

BRASIL. Banco do Brasil renegocia dívidas em atraso pela internet. Disponível em: http://www.brasil.gov.br/economia-e-emprego/2015/07/banco-do-brasil-renegocia-dividas-ematraso-pela internet?TSPD_101_R0=04c1fdd9a3d0b10fa2a77339260a7fc9o9w0000000000000000dcd3ddb5 ffff00000000000000000000000000005a9f192a00b1caf5d2. Acesso em: 06 mar. 2017.

CONSELHO NACIONAL DE JUSTIÇA. Justiça em números 2017. Brasília: CNJ, 2017. Disponível em:

http://www.cnj.jus.br/files/conteudo/arquivo/2017/09/e5b5789fe59c137d43506b2e4ec4ed67.pdf. Acesso em: 24 fev. 2018.

CONSELHO NACIONAL DE JUSTIÇA. Justiça em números 2017: Destaques. Brasília: CNJ, 2017. Disponível em: http://www.cnj.jus.br/files/conteudo/arquivo/2017/09/e5b5789fe59c137d43506b2e4ec4ed67.pdf. Acesso em: 08 mar. 2018. 
CONSELHO NACIONAL DE JUSTIÇA. Justiça em números 2017. Brasília: CNJ, 2016. Disponível em:

http://www.cnj.jus.br/files/conteudo/arquivo/2017/12/b60a659e5d5cb79337945c1dd137496c.pdf . Acesso em: 24 fev. 2018.

ÉPOCA NEGÓCIOS. A partir da ideia de um funcionário, Banco do Brasil recupera R \$ 1,5 bilhão. Disponível em: https://epocanegocios.globo.com/Informacao/Acao/noticia/2015/10/partirda-ideia-de-um-funcionario-banco-do-brasil-recupera-r-15-bilhoes.html. Acesso em: 05 mar. 2018.

EXAME. As 10 competências mais raras entre profissionais brasileiros. Disponível em: https://examecom/carreira/as-10-competencias-mais-raras-entre-profissionais-brasileiros/. Acesso em: 06 ago. 2020.

FISHER, Roger; URY, William; PATTON, Bruce. Como chegar ao sim: como negociar acordos sem fazer concessões. 3. ed. Rio de Janeiro: Solomon, 2014.

FISHER, Roger; SHAPIRO, Daniel. Além da razão: a força da emoção na solução de conflitos. Tradução de Arão Sapiro, Rio de Janeiro: Imago, 2009.

GASPARINI, Claudia. As 10 competências mais raras entre profissionais brasileiros. Revista Exame, N/a, v. 0, n. 0, p.0-0, out. 2016. Disponível em: http://exame.abril.com.br/carreira/as-10competencias-mais-raras-entre-profissionais-brasileiros/. Acesso em: 15 set. 2017.

GUNTHER, Luiz Eduardo; MACHADO, Luciana Aboim; MEDRADO, Paloma. Breve análise do método de negociação de Harvard e sua utilização na solução de conflitos e sua aplicabilidade na mediação judicial. Administração de Empresas em Revista, [S.l.], v. 1, n. 15, p. 170-187, abr. 2019. Disponível em:

http://revista.unicuritiba.edu.br/index.php/admrevista/article/view/4029/371372348 Acesso em: 04 ago. 2020.

G1. Enel realiza feirão de negociação de dívidas no Ceará. Disponível em: https://g1.globo.com/ceara/noticia/enel-realiza-feirao-de-negociacao-de-dividas-no-ceara.ghtml. Acesso em: 15 mar. 2018.

MALHEIROS, Rafael Taranto. A Formalização da Propriedade Imobiliária e a Oferta de Crédito: a regularização fundiária urbana como vetor de desenvolvimento econômico. Revista da Procuradoria-Geral do Banco Central, v. 12, n. 2, p. 136-152, mar. 2019. Disponível em: https://revistapgbc.bcb.gov.br/index.php/revista/article/view/956. Acesso em: 05 ago. 2020.

MORAES, Maria Celina Bodin de. O conceito de dignidade humana: substrato axiológico e conteúdo normativo. In: SARLET, Ingo Wolfgang Sarlet. Constituição, direitos fundamentais e direito privado. 3 ed. Porto Alegre: Livraria do Advogado, 2010.

REIS, Cristiane de Souza. A empatia na mediação: a contribuição da comunicação não violenta. Jornal Jurídico, Madeira, v. 2, n. 1, p. 03-28, fev. 2019. Disponível em: https://revistas.ponteditora.org/index.php/j2/article/view/194. Acesso em: 05 ago. 2020.

RIZZARDO, Arnaldo. Contratos de crédito bancário. 4. ed. São Paulo: RT, 2003. 
SADDI, Jairo. Crédito e Judiciário no Brasil. São Paulo: Quartier Latin, 2007.

SALES, Lília Maia de Morais. Mediare: um guia prático para mediadores. 3. ed. Rio de Janeiro: GZ Editora, 2010.

SALES, Lília Maia de Morais; ANDRADE, Luana Silveira da. A mediação de conflitos e o direito: desenvolvendo habilidades a essa nova realidade. Revista Prima Facie, João Pessoa, v. 16, n. 33, p. 01-29, set-dez 2017. Disponível em:

http://www.periodicos.ufpb.br/index.php/primafacie/article/view/37058/18760. Acesso em: 26 mar. 2018.

SALES, Lília Maia de Morais; LIMA, Gabriela Vasconcelos. Mediação Comunitária: uma contribuição na busca pelos objetivos do desenvolvimento sustentável no estado do Ceará. Revista Direito, Estado e Sociedade, Rio de Janeiro, n. 54, p. 260-278, jan-jun 2019. Disponível em: https://revistades.jur.puc-rio.br/index.php/revistades/article/view/945/553. Acesso em: 05 ago. 2020.

SARMENTO, Daniel. Direitos Fundamentais e Relações Privadas. 2.ed. Rio de Janeiro: Lumen Juris, 2010.

SCHUMPETER, Joseph. The Theory of Economic Devefopment. Oxford: Oxford University Press, 1978.

SCHWAB, Klaus. A quarta revolução industrial. Tradução de Daniel Moreira Miranda. São Paulo: Edipro, 2016.

O POVO. COELCE realiza feirão de negociação de dívidas em todo o Ceará. Disponível em: https://www.opovo.com.br/noticias/fortaleza/2016/02/coelce-realizara-feirao-de-negociacao-dedividas-em-todo-o-ceara.html. Acesso em: 15 mar. 2018.

TASKEN. Tasken Debt. Disponível em: http://www.tasken.com/solucoes/tasken-debt/. Acesso em: 12 mar. 2018.

THOMAZI, LUCIANA DA CRUZ; PAULA, Luiz Fernando de. Uma análise da Desigualdade do Crédito entre os Municípios do Estado do Rio de Janeiro: 2000-2014. Revista Análise Econômica, Porto Alegre, v. 38, n. 75, p. 103-130, mar. 2020. Disponível em: https://www.seer.ufrgs.br/AnaliseEconomica/article/view/73601/56888. Acesso em: 05 ago. 2020 .

WORLD ECONOMIC FORUM. The 10 skills you need to thrive in the Fourth Industrial Revolution. Disponível em: https://www.weforum.org/agenda/2016/01/the-10-skills-you-need-tothrive-in-the-fourth-industrial-revolution/. Acesso em: 03 abr. 2018. 